\title{
The Costs of Psoriasis Medications
}

\author{
Anssi Mustonen $\cdot$ Kalle Mattila $\cdot$ Mauri Leino $\cdot$ \\ Leena Koulu $\cdot$ Risto Tuominen
}

To view enhanced content go to www.dermtherapy-open.com

Received: November 5, 2013 / Published online: December 13, 2013

(c) The Author(s) 2013. This article is published with open access at Springerlink.com

\section{ABSTRACT \\ multiple treatment options on a patient's quality of life.}

Introduction: Psoriasis is a chronic disease, which contributes to the economic burden on health care. The distribution of psoriasis medication costs and the quality of life in these patients has been estimated to be around $20 \%$ of total costs.

Objectives: To estimate the economic distribution of medications and the impact of

Electronic supplementary material The online version of this article (doi:10.1007/s13555-013-0040-z) contains supplementary material, which is available to authorized users.

A. Mustonen $(\varangle) \cdot$ K. Mattila $\cdot$ M. Leino $\cdot$ L. Koulu Department of Dermatology, Turku University Hospital, University of Turku, Lemminkäisenkatu 1, 20014 Turku, Finland

e-mail: atmust@utu.fi

R. Tuominen

Department of Public Health, University of Turku and Primary Health Care Unit, Turku, Finland

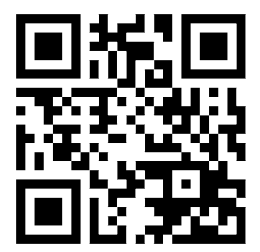

Enhanced content for this article is available on the journal web site: www.dermtherapy-open.com
Materials and methods: The study was based on 236 Finnish psoriasis patients. The Finnish Social Insurance Institution had databases for all psoriasis related medications purchased. Each purchase, during the 1-year study period (1 October 2009-30 September 2010), was recorded and analyzed. The dermatological quality-of-life index was collected from the medical records.

Results: Total medication costs were $€ 1,083$ per year per patient. Topical treatments were the most often purchased medication and they comprised $18 \%$ of the total medication costs. Ten percent of the patients needed 3 or more medication changes during the 1-year study period. Biologics were used only by $5 \%$ of patients, but they produced $67 \%$ of total medication costs. Patients needing various treatments had higher medication costs and a poorer quality of life.

Conclusion: A small number of patients generated a great sum of medication costs partly due to the need to change medications. These patients had the worst quality-of-life index scores. Biologics formed a major cost component. 
Keywords: Biologics; Cost; Dermatology; Dermatology Life Quality Index; Pharmacotherapy; Psoriasis

\section{INTRODUCTION}

Psoriasis (Ps) is a chronic inflammatory disease with a global prevalence of $1.5-2.8 \%$ and around $6-30 \%$ of Ps patients also have psoriatic arthritis (PsA) [1-5]. Ps is treated with topical medications-corticosteroids and vitamin-D analogs, UV-phototherapy, systemic medications-methotrexate, acitretin and ciclosporin or with biological medications [6, 7]. Mild Ps is treated with topical medications. Moderate-to-severe Ps is treated with systemic medications or UV-phototherapy or with a combination of both [6, 7]. Use of biologic medications is recommended as second-line medications or only when traditional systemic medications or UV-phototherapy are not successful $[6,8]$. It has been suggested that patients with severe Ps should be treated more with systemic medications [9].

In the Finnish health care system, patients with mild Ps are treated mainly in primary level health care. Moderate and severe Ps patients are treated in tertiary or secondary level dermatological clinics. However, these patients can also be treated in primary level settings, particularly if they are responding to the treatment given. Medication costs are partly reimbursed to patients by the Finnish Social Insurer Institute.

Ps is a lifelong disease and leads to a considerable burden and expenses to health care [2, 9-14]. The cost-of-illness estimations of the total costs have a wide range extending from $€ 1,079$ to $€ 8,371$ [8-13]. The proportion of medications costs is approximately $20 \%$ of total costs [10, 13, 15-17]. Biologic medications increase the total costs and the proportion of medication costs [18]. Often the estimated medication costs are based on assumptions extrapolated from cross-sectional questionnaire data. There is no previous information about the medication costs of Ps in Finland. The costs of all Ps medications, not just biologics, have been increasing significantly during the past decade [19]. Treatment failure is a major factor, which increases the treatment costs [13, 20]. Advancing from the safest medication available to more potent medicines, results in multiple treatment failure for many patients, as combinations or more efficient medications are often needed to clear Ps [20]. Intolerance to a specific medication may also lead to treatment failure and a decision to advance to another therapy [20]. Patients failing to respond to treatments had the highest total costs [13].

The aim of this study was to estimate the economic distribution of Ps medications from a societal perspective and to assess the dermatological quality of life in Ps patients needing multiple treatments.

\section{MATERIALS AND METHODS}

The sample was based on patients whom had visited the Department of Dermatology in Turku University Hospital, Finland, between 1 October 2009 and 30 September 2010. They were all diagnosed to have Ps or PsA. In the Finnish health care system, patients with mild level Ps are treated at primary health care settings and only moderate-to-severe cases are referred to tertiary level hospital for further treatment. A total of 498 patients attended the clinic during the study period (428 had Ps and 70 had PsA). The patients were sent a questionnaire by mail. A total of 262 patients 
completed the questionnaire $(52.6 \%$ of the total study sample). Patients with Ps or PsA participated equally [21].

\section{Compliance with Ethics}

The ethical committee of The Hospital District of Southwest Finland approved the study. The patients received a written description of the sampling procedure and study purpose, as well as the planned use and storage of the information they were to provide. The patients were asked to give a written consent to use their medical records for the study.

All procedures followed were in accordance with the ethical standards of the responsible committee on human experimentation (institutional and national) and with the Helsinki Declaration of 1975, as revised in 2000 and 2008. Informed consent was obtained from all patients for being included in the study.

\section{Questionnaire}

Socio-demographic background was collected with the questionnaire. The questions included gender, age, home municipality, number of persons living in the same household, income level and disease duration.

\section{Clinical Data}

Out of the 262 patients who completed the questionnaire, 26 patients did not give written consent for the right to use their medical records. Clinical information was collected from the 236 patients' medical records who gave consent, for the same time period that was covered in the questionnaire data. The information consisted of Psoriasis Area Severity Index (PASI), Dermatology Life
Quality Index (DLQI), the diagnosis [ICD-10 (International Statistical Classification of Diseases and Related Health Problems)] and whether a patient had received UVphototherapy during the study period. PASI describes the patient's Ps severity and area, and the PASI values rise with increasing severity. PASI values are based on a scale from 0 to 72 . Higher DLQI values represent a poor quality of life. DLQI values are based on a scale from 0 to 30. Laboratory costs were collected with a separate retrieval from the hospital's patient records. They consisted of all the tests (not only monitoring) ordered by the dermatological clinic during the study period. Laboratory costs were from the whole study period and they could not be linked to a specific medication causally.

\section{Medication Use}

The Finnish Social Insurance Institution (FSII) reimburses part of a patient's medicine expenses. In practice, all Finnish Ps patients receive reimbursements for all their Ps-related medications and emollients no matter who prescribes the medications. FSII provided data of all Ps-related medication purchases of the study patients who had given consent. Psrelated medication in this study comprised all biologic medications (including adalimumab, etanercept, infliximab, and ustekinumab), traditional systemic medications (including methotrexate, acitretin, and ciclosporin), topical drugs (including vitamin-D analogs, corticosteroid creams and combinations of these), leflunomide, topical fungal medicine, antihistamines and emollients. All purchases during the study period between 1 October 2009 and 30 September 2010 were recorded. FSII records of each purchase contained the total cost of the medication/emollient and the 
ATC-code (Anatomical Therapeutic Chemical Classification) of the purchase as well as the amount of packages purchased. ATC-codes were used to identify each drug. Drugs were clustered based on their active ingredients regardless of their brand names.

\section{Treatment Options}

To analyze how many different types of treatments each patient used, treatment options were formed as following. All topical medications (not including emollients) were pooled as one treatment option. Traditional systemic medications (methotrexate, acitretin, and cyclosporine) were analyzed separately and each of them formed one treatment option. All biological medications formed one treatment option. They were pooled because of the low number of patients using them. UVphototherapy was considered as one treatment option. Emollients, fungal medicines, antihistamines and other medications, which might have been used as supportive medications, were not considered as a separate treatment option. However, these medications were included for the total cost computations of medications.

\section{Medication Costs}

The total cost of the drugs was used as the societal cost in all calculations without any reimbursement deductions. All medication costs were analyzed for the annual cost of medications per patient. Only the drugs in each treatment option were included for the cost calculations, when analyzing the costs of different treatment options. UV-phototherapy's costs were not considered in any of the cost analyses.

\section{Statistical Analysis}

In the analyses of the subgroup with PASI and DLQI values, all patients without recorded PASI or DLQI values were excluded. If several PASI or DLQI values were recorded for a patient during the study period, the arithmetic mean values were computed and used. When analyzing the subgroups with recorded PASI values, patients were divided by the median value into more severe (PASI $>5.5, n=37$ ) and less severe psoriasis $(\mathrm{PASI} \leq 5.5, n=35)$. The statistical evaluation of the data was based on Chisquare test for proportions and Student's $t$ test for means. The distribution of the DLQI values was skewed and to account for this, a Spearman's non-parametric correlation was used.

\section{RESULTS}

Patients in the study sample were on average 57 years old, 55\% were male. Fifty percent of patients were retired, 38\% currently working and $13 \%$ unemployed. On average they had had Ps for 20 years and $14 \%$ of patients had PsA. The mean DLQI score was 11.0 and the mean PASI score 6.5 .

Total medication costs were $€ 1,083$ per year per patient. Topical treatments were most often purchased medications and they comprised $18 \%$ of the total medication costs (Table 1 ). Biologics and ciclosporin were the most expensive medications and were rarely used (Table 1). Biologics were used only by $5 \%$ of the patients, but they produced $67 \%$ of total medication costs. Methotrexate was used by $18 \%$ of patients, yet it produced only $0.6 \%$ of all medication costs. Patients using ciclosporin and methotrexate had higher laboratory costs than patients not using them (Table 1). 
Table 1 The cost-of-treatment options (not including other psoriasis-related medications or emollients) and laboratory tests for patients receiving each medication and the proportion of the patients who had received each medication

\begin{tabular}{lccc}
\hline & Medication cost $(\boldsymbol{\epsilon})$ & $\begin{array}{l}\text { Percentage of patients receiving } \\
\text { each medication }(\%)\end{array}$ & $\begin{array}{c}\text { Laboratory } \\
\text { cost }(\boldsymbol{\epsilon})\end{array}$ \\
\hline Acitretin & $351(n=46)$ & 20 & 63 \\
Ciclosporin & $1,420(n=3)$ & 1 & 213 \\
Methotrexate & $39(n=43)$ & 18 & $124^{*}$ \\
Biologics & $15,630(n=11)$ & 5 & 58 \\
Topical treatments & $242(n=194)$ & 83 & $57^{*}$ \\
\hline
\end{tabular}

${ }^{*} p<0.05$ significantly higher than patients not receiving the medication

UV-phototherapy was a treatment option for $36 \%$ of the patients. Out of the study group, $9 \%$ did not receive any treatment option, 29\% received one, $51 \%$ two, $9 \%$ three and $1 \%$ of the patients received four treatment options during the 1-year follow-up period. Topical treatment was most often combined with other treatment options. Patients receiving multiple various treatment options had considerably higher costs than patients receiving fewer treatment options (Fig. 1), the differences were significant $(p<0.05)$ among all three groups. Patients who received more treatment options during the 1-year follow-up period had a significantly $(p<0.05)$ lower quality of life measured with DLQI $(r=0.384)$ (Fig. 2). PASI scores did not correlate with the number of different treatments. Patients not receiving any kind of treatment were more likely to be unemployed $(p<0.05)$, irrespective of level of income.

Patients with more severe Ps $(n=35)$ had higher total medication costs $(€ 2,559)$ than patients $(n=37)$ with less severe Ps $(€ 1,375)$ $(p<0.05)$. When each treatment option was analyzed separately, only the costs of topical medications was significantly $(p<0.05)$ higher for those with more severe psoriasis (€394) than patients with less severe Ps $(€ 163)$. There was no

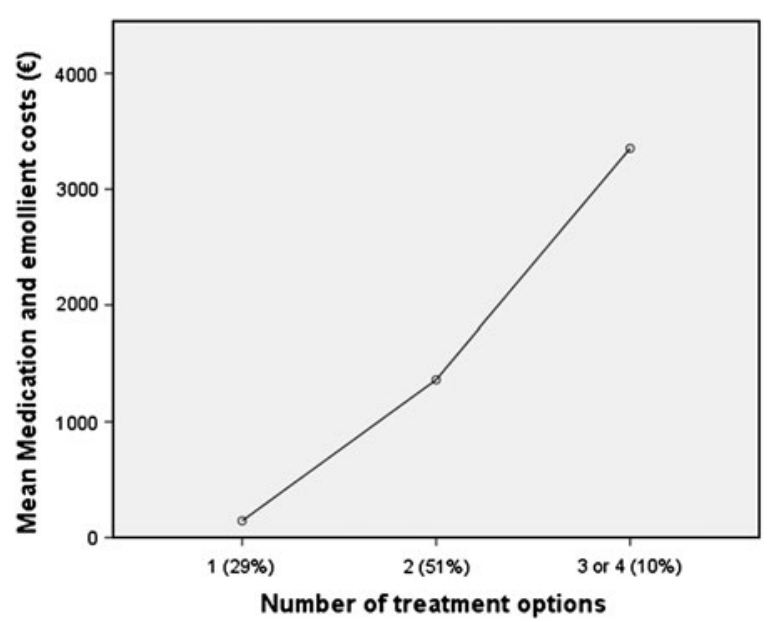

Fig. 1 The average costs of all medications and emollients as a function of the number of treatment options (only acitretin, ciclosporin, methotrexate, biologics, topical treatments and UV-phototherapy) received during the 1-year study period. The number of treatment options represents the number of different medications or UV therapy administered to the patient, with the percentage of patients in each group in parenthesis. Differences between all treatment groups were statistically significant $(p<0.05)$

significant difference in the probability of receiving topical treatments between the two groups, but there was a significant $(p<0.001)$ difference in the total number of packages of topical medications bought between less (mean 2.4 packages/year) and more severe (8.7 packages/ year) Ps patients. Methotrexate, ciclosporin and biologic medications formed higher statistically 


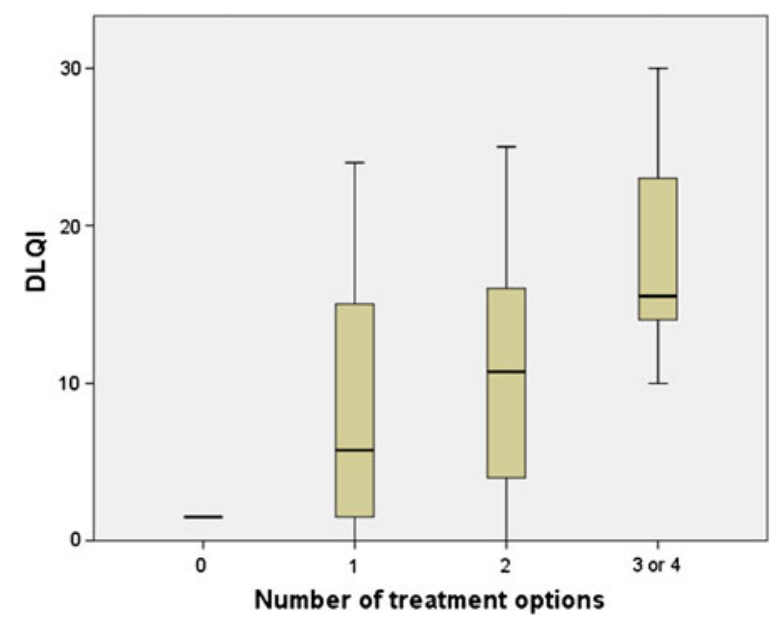

Fig. 2 Dermatological Life Quality index (DLQI) values increased by the number of treatment options to the patient during the 1-year study period. A significant $(p<0.05)$ correlation $(r=0.384)$ existed between DLQI and the number of treatment options

non-significant (NS) $(p=0.19-0.5)$ medications costs for patients with more severe Ps. There was no statistically significant difference in the rate of acitretin prescriptions for participants between different severity groups.

Men and women had equal probability to receive topical medications. However, among those using them, men used more and this led to significantly $(p<0.05)$ higher costs $(€ 299)$ for men than women $(€ 171)$. Biologics and ciclosporin were only purchased by Ps patients, thus producing higher (NS, $p=0.1-0.2)$ total costs of medications for Ps patients $(€ 1,331)$ than PsA patients $(€ 316)$.

\section{DISCUSSION}

The results of this study may indicate that treatment failure or not finding an effective treatment for a Ps patient produces a significant increase in medication costs and a higher DLQI score. Medication costs can be excluded as a cause for the higher DLQI score because in Finland, social insurance limits expenses. This strongly suggests that treatment failure could lead to a Ps patient's decreased quality of life.

In this study, UV-phototherapy costs were not included in medication cost computations. However, if a patient had received UVphototherapy, they had a higher probability to have received multiple treatment options. This indicates that the higher the number of treatment options contributes to a higher cost to the patients. Prior studies have suggested that treatment failure was likely for patients receiving systemic therapies or UVphototherapy and it produces high costs in Ps treatment $[20,22]$. Our study results are in line with those studies.

Dermatology Life Quality Index may be a better index to predict higher costs than PASI in patients needing multiple treatment options. A recent study by Ekelund et al. [16] estimated that high DLQI scores are associated with high medication costs. In this study, PASI scores were not significantly associated with medication costs. Staidle et al. [23] suggest that DLQI or other methods of measuring a patient's quality of life should be integrated in cost-analysis of medications and treatments. However, PASI values predicted the quantities of medications used better than DLQI. The number of patient records available in this study, which had PASI or DLQI index scores, was limited, which may be a source of selection bias. These findings should be considered cautiously and further studies are warranted. In this sample, only few patients had PASI values above 10, and using such high index value for categorizing would have produced a subgroup of severe Ps patients which is too small for statistical analyses. Owing to this the subgroups were defined as less and more severe psoriasis patients, instead of calling them moderate and severe.

In prior studies, annual costs of medications per psoriasis patient vary from $€ 107$ to $€ 3,132$ 
$[10,13,15,17,24,25]$. Our results are similar to a study by Berger et al. [15] and Colombo et al. [10] with costs in the middle of the range. In the study by Augustin et al. [24] where the costs were $€ 107$ per patient, the sample comprised general Ps patients, thus a majority of patients had mild Ps unlike most other studies, resulting in lower medication costs. In Sohn et al.'s [13] study, a strict inclusion criterion led to a study sample with very severe psoriasis with a mean PASI of 18.2 and high medication costs of $€ 2,014$ per year. A higher proportion of the study population using biologic medications increased the overall medications costs significantly. In Ghatnekar et al.'s [17] study, biologic medications were received by $16 \%$ of patients and the costs for biologics were, for the entire population, on average $€ 2,386$ per patient per year. In our study, the costs for all medications were significantly lower, partly due to the lower number of patients receiving biologics.

Here, the proportion of biologics prescribed was low when compared to other studies [17, 26, 27]. None of the PsA patients received biologics. Some PsA patients might have been treated by rheumatologists instead of dermatologists and thus, such patients were not selected. However, the findings in this study indicate that biologics should be considered more often for patients that have failed to respond to other systemic medications, as they had considerably lower quality-of-life indices. Some studies [6] suggest that biologics should be used only if traditional systemic therapies have proven ineffective or have produced side effects, but other studies [8] suggest that biologics should be considered as second-line treatment if UV-phototherapy is not effective enough for severe psoriasis patients due to biologics good safety profile and effectiveness.
Increasing the number of patients receiving biologics increases the costs of medication dramatically $[19,28]$. Our findings are in line with the results of Beyer et al. [19]. As in our study, the patients that received biologic medications had ten times higher medication costs than patients that received traditional systemic or topical treatments.

Although almost every fifth patient had purchased methotrexate during the follow-up period, their costs to the society were marginal. Laboratory and outpatients costs are higher for patients using methotrexate because of the required regular laboratory tests and possible need for liver biopsies $[6,8]$. The adverse effects of drugs are difficult to incorporate in cost comparison studies, but they play a significant role in decision-making of clinical practice [8]. In this study, laboratory costs were also higher for patients receiving methotrexate than other patients, but our data allowed only indicative estimations as causality of laboratory costs with specific medications could not be formed.

Present study data were collected from the Hospital District of Southwest Finland only. However, the findings should be generalizable for the whole of Finland, as there is no reason to assume that Ps patients in various parts of the country would be different. Furthermore, clinical treatment guidelines are common throughout the country.

\section{CONCLUSION}

Patients needing multiple different treatments generate high costs and have worse quality of life. A small number of patients generate the majority of medication costs. Although biologics are expensive, these hold potential to improve the quality of life in patients with severe Ps. 


\section{ACKNOWLEDGMENTS}

Dr. Mustonen is the guarantor for this article, and takes responsibility for the integrity of the work as a whole.

This study was supported by grants from the Hospital District of Southwest Finland. Robert M. Badeau, Ph.D. from the University of Turku Language Centre performed the linguistic checking for this manuscript. A. Mustonen, K. Mattila, M. Leino, L. Koulu and R. Tuominen declare that they have no conflict of interest.

\section{Compliance with ethics. The ethical} committee of The Hospital District of Southwest Finland approved the study. The patients received a written description of the sampling procedure and study purpose, as well as the planned use and storage of the information they were to provide. The patients were asked to give a written consent to use their medical records for the study.

All procedures followed were in accordance with the ethical standards of the responsible committee on human experimentation (institutional and national) and with the Helsinki Declaration of 1975 , as revised in 2000 and 2008. Informed consent was obtained from all patients for being included in the study.

Open Access. This article is distributed under the terms of the Creative Commons Attribution Noncommercial License which permits any noncommercial use, distribution, and reproduction in any medium, provided the original author(s) and the source are credited.

\section{REFERENCES}

1. Raychaudhuri SP, Farber EM. The prevalence of psoriasis in the world. J Eur Acad Dermatol Venereol. 2001;15(1):16-7.
2. Radtke MA, Augustin M. Economic considerations in psoriasis management. Clin Dermatol. 2008; 26(5):424-31.

3. Gelfand JM, Gladman DD, Mease PJ, Smith N, Margolis DJ, Nijsten T, et al. Epidemiology of psoriatic arthritis in the population of the United States. J Am Acad Dermatol. 2005;53(4):573.

4. Kaipiainen-Seppanen O. Incidence of psoriatic arthritis in Finland. Br J Rheumatol. 1996;35(12): 1289-91.

5. Lambert J, Dowlatshahi EA, de la Brassinne $\mathrm{M}$, Nijsten T. A descriptive study of psoriasis characteristics, severity and impact among 3,269 patients: results of a Belgian cross sectional study (BELPSO). Eur J Dermatol. 2012;22(2):231-7.

6. Hankin C, Feldman S, Szczotka A, Stinger R, Fish L, Hankin D. A cost comparison of treatments of moderate to severe psoriasis. Drug Benefit Trends. $2005 ; 17: 200-14$.

7. Feldman SR, Garton R, Averett W, Balkrishnan R, Vallee J. Strategy to manage the treatment of severe psoriasis: considerations of efficacy, safety and cost. Expert Opin Pharmacother. 2003;4(9):1525-33.

8. Miller DW, Feldman SR. Cost-effectiveness of moderate-to-severe psoriasis treatment. Expert Opin Pharmacother. 2006;7(2):157-67.

9. Augustin M, Radtke MA. Health economic issues in Psoriasis. Expert Rev Dermatol. 2008;3:19.

10. Colombo G, Altomare G, Peris K, Martini P, Quarta $\mathrm{G}$, Congedo $\mathrm{M}$, et al. Moderate and severe plaque psoriasis: cost-of-illness study in Italy. Ther Clin Risk Manage. 2008;4(2):559-68.

11. Raho G, Koleva DM, Garattini L, Naldi L. The burden of moderate to severe psoriasis: an overview. Pharmacoeconomics. 2012;30(11): 1005-13.

12. Raval K, Lofland JH, Waters H, Piech CT. Disease and treatment burden of psoriasis: examining the impact of biologics. J Drugs Dermatol. 2011;10(2): 189-96.

13. Sohn S, Schoeffski O, Prinz J, Reich K, Schubert E, Waldorf $\mathrm{K}$, et al. Cost of moderate to severe plaque psoriasis in Germany: a multicenter cost-of-illness study. Dermatology. 2006;212(2):137-44.

14. Nijsten T, Looman CW, Stern RS. Clinical severity of psoriasis in last 20 years of PUVA study. Arch Dermatol. 2007;143(9):1113-21.

15. Berger K, Ehlken B, Kugland B, Augustin M. Cost-ofillness in patients with moderate and severe chronic 
psoriasis vulgaris in Germany. J Dtsch Dermatol Ges. 2005;3(7):511-8.

16. Ekelund M, Mallbris L, Qvitzau S, Stenberg B. A higher score on the dermatology life quality index, being on systemic treatment and having a diagnosis of psoriatic arthritis is associated with increased costs in patients with plaque psoriasis. Acta Derm Venereol. 2013;93:684-8.

17. Ghatnekar O, Ljungberg A, Wirestrand LE, Svensson A. Costs and quality of life for psoriatic patients at different degrees of severity in southern Sweden-a cross-sectional study. Eur J Dermatol. 2012;22(2):238-45.

18. Driessen RJ, Bisschops LA, Adang EM, Evers AW, Van De Kerkhof PC, De Jong EM. The economic impact of high-need psoriasis in daily clinical practice before and after the introduction of biologics. Br J Dermatol. 2010;162(6):1324-9.

19. Beyer V, Wolverton SE. Recent trends in systemic psoriasis treatment costs. Arch Dermatol. 2010;146(1):46-54.

20. Pearce DJ, Nelson AA, Fleischer AB, Balkrishnan R, Feldman SR. The cost-effectiveness and cost of treatment failures associated with systemic psoriasis therapies. J Dermatolog Treat. 2006;17(1):29-37.

21. Mattila K, Leino M, Mustonen A, Koulu L, Tuominen R. Influence of psoriasis on work. Eur J Dermatol. 2013;23(2):208-11.

22. Feldman SR, Evans C, Russell MW. Systemic treatment for moderate to severe psoriasis: estimates of failure rates and direct medical costs in a north-eastern US managed care plan. J Dermatolog Treat. 2005;16(1):37-42.

23. Staidle JP, Dabade TS, Feldman SR. A pharmacoeconomic analysis of severe psoriasis therapy: a review of treatment choices and cost efficiency. Expert Opin Pharmacother. 2011;12(13):2041-54.

24. Augustin M, Glaeske G, Schafer I, Rustenbach SJ, Hoer A, Radtke MA. Processes of psoriasis health care in Germany-long-term analysis of data from the statutory health insurances. J Dtsch Dermatol Ges. 2012;10(9):648-55.

25. Carrascosa JM, Pujol R, Dauden E, HernanzHermosa JM, Bordas X, Smandia JA, et al. A prospective evaluation of the cost of psoriasis in Spain (EPIDERMA project: phase II). J Eur Acad Dermatol Venereol. 2006;20(7):840-5.

26. Levy AR, Davie AM, Brazier NC, Jivraj F, Albrecht LE, Gratton D, et al. Economic burden of moderate to severe plaque psoriasis in Canada. Int J Dermatol. 2012;51(12):1432-40.

27. Meyer N, Paul C, Feneron D, Bardoulat I, Thiriet C, Camara C, et al. Psoriasis: an epidemiological evaluation of disease burden in 590 patients. J Eur Acad Dermatol Venereol. 2010;24(9):1075-82.

28. Fonia A, Jackson K, Lereun C, Grant DM, Barker JN, Smith $\mathrm{CH}$. A retrospective cohort study of the impact of biologic therapy initiation on medical resource use and costs in patients with moderate to severe psoriasis. Br J Dermatol. 2010;163(4):807-16. 